\title{
Curcumin activates autophagy and attenuates oxidative damage in EA.hy926 cells via the Akt/mTOR pathway
}

\author{
SHOUYU GUO ${ }^{1,2^{*}}$, MINGZHI LONG ${ }^{2 *}$, XIUZHEN LI $^{2}$, SHUSHU ZHU ${ }^{2}$, MIN ZHANG $^{2}$ and ZHIJIAN YANG ${ }^{1,3}$ \\ ${ }^{1}$ Department of Cardiology, The First Affiliated Hospital of Nanjing Medical University, Nanjing, Jiangsu 210029; \\ ${ }^{2}$ Department of Cardiology, The Second Affiliated Hospital of Nanjing Medical University, Nanjing, Jiangsu 210011; \\ ${ }^{3}$ Department of Geriatrics, The First Affiliated Hospital of Nanjing Medical University, Nanjing, Jiangsu 210029, P.R. China
}

Received January 20, 2015; Accepted November 5, 2015

DOI: $10.3892 / \mathrm{mmr} .2016 .4796$

\begin{abstract}
Curcumin, which is the effective component of turmeric (Curcuma longa), has previously been shown to exert potent antioxidant, antitumor and anti-inflammatory activities in vitro and in vivo. However, the mechanism underlying the protective effects of curcumin against oxidative damage in endothelial cells remains unclear. The present study aimed to examine the effects of curcumin on hydrogen peroxide $\left(\mathrm{H}_{2} \mathrm{O}_{2}\right)$-induced apoptosis and autophagy in EA.hy926 cells, and to determine the underlying molecular mechanism. Cultured EA.hy926 cells were treated with curcumin (5-20 $\mu \mathrm{mol} / \mathrm{l}) 4 \mathrm{~h}$ prior to and for $4 \mathrm{~h}$ during exposure to $\mathrm{H}_{2} \mathrm{O}_{2}(200 \mu \mathrm{mol} / \mathrm{l})$. Oxidative stress resulted in a significant increase in the rate of cell apoptosis, which was accompanied by an increase in the expression levels of caspase-3 and B-cell lymphoma 2 (Bcl-2)-associated $\mathrm{X}$ protein (Bax), and a decrease in the expression levels of Bcl-2. Treatment with curcumin ( 5 or $20 \mu \mathrm{mol} / \mathrm{l}$ ) significantly inhibited apoptosis, and reversed the alterations in caspase-3, Bcl-2 and Bax expression. Furthermore, curcumin induced autophagy and microtubule-associated protein 1A/1B-light chain 3-II expression, and suppressed the phosphorylation of Akt and mammalian target of rapamycin (mTOR). These results indicated that curcumin may protect cells against oxidative stress-induced damage through inhibiting apoptosis and inducing autophagy via the Akt/mTOR pathway.
\end{abstract}

Correspondence to: Professor Zhijian Yang, Department of Cardiology, The First Affiliated Hospital of Nanjing Medical University, 300 Guangzhou Street, Nanjing, Jiangsu 210029, P.R. China

E-mail: zhijianyangnj@njmu.edu.cn

*Contributed equally

Key words: curcumin, EA.hy926 cells, oxidative damage, autophagy, apoptosis, Akt/mTOR pathway

\section{Introduction}

Curcumin (diferuloylmethane), which is the main component extracted from turmeric (Curcuma longa), is a traditional medicinal plant that exerts various biological functions (1-3), including anti-inflammatory, antioxidant, anticancer and cardioprotective effects. The exact mechanism by which curcumin exerts these effects remains to be elucidated; however, the antioxidant activity of the hydrophobic polyphenol appears to be the essential component underlying its pleiotropic biological effects (4). Previous studies have demonstrated that curcumin is able to ameliorate the production of reactive oxygen species (ROS) and lipid peroxidation in various models of oxidative damage in cardiac tissue $(5,6)$. Endothelial cell injury is a critical step in the development of atherosclerosis and hypertension (7). In addition, it has previously been reported that curcumin may attenuate oxidative damage in endothelial cells (8); however, the underlying mechanism remains unclear.

Apoptosis, which is the process of programmed cell death, leads to the rapid degradation of cellular structures and organelles (9). Furthermore, autophagy is a highly conserved cellular process that comprises bulk degradation and recycling of cytoplasmic components, including long-lived proteins and organelles (10). The functional relationship between apoptosis and autophagy is complex. Autophagy-induced cytoprotection is the basic cellular function of autophagy in eukaryotic cells; however, some stressors, including oxidative stress, induce excessive autophagy that may result in heart disease (11). Active autophagy can be either pro-survival (adaptive) or anti-survival (maladaptive). Complete abrogation of cardiomyocyte autophagy is detrimental to cardiac homeostasis under basal conditions, whereas upregulation of autophagy in failing heart tissue is an adaptive response that protects cells from hemodynamic stress (12). Autophagy has distinct roles in various types of heart disease, in certain conditions, the response is beneficial, in other cases, it can promote disease progression. Targeting autophagy in the cardiovascular system may be therapeutically relevant. It has previously been hypothesized that induction of autophagy and inhibition of apoptosis may be the mechanism underlying the protective effects of curcumin against oxidative stress.

The phosphoinositide 3-kinase/Akt/mammalian target of rapamycin (PI3K/Akt/mTOR) pathway is closely associated 
with the regulation of autophagy for its role in cell survival, proliferation and differentiation (13). mTOR, which is an amino acid, ATP and hormone receptor, may inhibit autophagy. Conversely, inhibition of mTOR by nutritional deficiency or the direct use of rapamycin may activate autophagy-related 1 , and thus promote autophagy $(14,15)$. By modulating the mTOR signaling pathway, cell apoptosis and autophagy can be adjusted in numerous cells.

The aim of the present study was to determine the molecular mechanism of action of curcumin in $\mathrm{H}_{2} \mathrm{O}_{2}$-treated EA.hy926 cells. The EA.hy 926 human umbilical vein endothelial cell line was pretreated with various concentrations of curcumin prior to hydrogen peroxide $\left(\mathrm{H}_{2} \mathrm{O}_{2}\right)$ stimulation, in order to explore the potential underlying mechanism. Alterations in the expression of autophagy and apoptosis-related proteins, cell viability, and activation of the Akt/mTOR pathway in curcumin-pretreated EA.hy926 cells were determined following $\mathrm{H}_{2} \mathrm{O}_{2}$ stimulation.

\section{Materials and methods}

Cell culture and induction of oxidative stress. The EA.hy926 cell line was purchased from the Cell Bank of the Chinese Academy of Science (Shanghai, China). The cells were cultured in Dulbecco's modified Eagle's medium (DMEM; Gibco; Thermo Fisher Scientific, Inc., Waltham, MA, USA) supplemented with $10 \%$ fetal bovine serum (Gibco; Thermo Fisher Scientific, Inc.), penicillin (10,000 units/1; Wisent Inc., Quebec, Canada) and streptomycin $(100,000 \mu \mathrm{g} / 1)$ at $37^{\circ} \mathrm{C}$ in an atmosphere containing $95 \%$ air $/ 5 \% \mathrm{CO}_{2}$. The media were changed every 2 days. The cells were allowed to grow to $80 \%$ confluence within $24 \mathrm{~h}$ prior to drug treatment. The cells were pretreated with curcumin (5-20 $\mu \mathrm{mol} / \mathrm{l}$; Sigma-Aldrich, St. Louis, MO, USA) for $4 \mathrm{~h}$, after which the medium was removed and replaced with medium containing various concentrations of curcumin alongside $200 \mu \mathrm{mol} / 1 \mathrm{H}_{2} \mathrm{O}_{2}$ (Nanjing Chemical Reagent, Co., Ltd., Nanjing, China). The medium of the control group was changed at $4 \mathrm{~h}$ and cells were not treated with curcumin or $\mathrm{H}_{2} \mathrm{O}_{2}$. Following an additional $4 \mathrm{~h}$ incubation at $37^{\circ} \mathrm{C}$, the cells were assessed.

Cytotoxicity assays. Cell viability was determined using the Cell Counting kit-8 (CCK-8) colorimetric assay (Dojindo Molecular Technologies, Inc., Kumamoto, Japan). Briefly, the cells were seeded into a 96-well cell culture plate $\left(1 \times 10^{4}\right.$ cells/well), and were pretreated with various concentrations of curcumin and $\mathrm{H}_{2} \mathrm{O}_{2}$. To measure cell viability, $10 \mu \mathrm{l}$ CCK-8 assay solution was added to each well, which contained $100 \mu \mathrm{l}$ medium, and the cells were incubated at $37^{\circ} \mathrm{C}$ for a further $4 \mathrm{~h}$. Subsequently the optical densities of the wells were measured at $540 \mathrm{~nm}$ using a microplate reader (ELx800; BioTek Instruments, Inc., Winooski, VT, USA).

Measurement of apoptosis using Hoechst 33258 staining. Chromatin condensation was detected by nuclear staining using Hoechst 33258. After pretreatment, the medium was removed and the cells were fixed with $500 \mu$ methyl hydrate at room temperature for $15 \mathrm{~min}$, before being washed three times with phosphate-buffered saline (PBS). The cells were then stained with $1 \mu \mathrm{l}$ Hoechst 33258 (5 mg/ml; Sigma-Aldrich) in $1 \mathrm{ml}$ basal medium and incubated at room temperature in the dark for $20 \mathrm{~min}$. Stained cells were visualized under a fluorescent microscope (excitation, $350 \mathrm{~nm}$; emission, $460 \mathrm{~nm}$; BX51; Olympus, Tokyo, Japan).

Determination of autophagosome formation. Autophagy is controlled by autophagosome formation (input) and autophagosome degradation (output), and the speed of autophagosome turnover is defined as autophagic flux. A fluorescein isothiocyanate (FITC)-labeled-microtubule-associated protein 1A/1B-light chain 3 (LC3) antibody (CYTO-ID ${ }^{\circledR}$ Autophagy Detection kit) was used to detect autophagosome formation using the CYTO-ID ${ }^{\circledR}$ Autophagy Detection kit (Enzo Life Sciences, Inc., Farmingdale, NY, USA), according to the manufacturers' protocol. The autophagy inducer rapamycin (500 nmol/1; CYTO-ID ${ }^{\circledR}$ Autophagy Detection kit), which is often used as a positive control of autophagy, was added to the cells for $18 \mathrm{~h}$ at $37^{\circ} \mathrm{C}$. The nuclei were then stained using 4',6-diamidino-2-phenylindole (Beyotime Institute of Biotechnology, Haimen, China). Subsequently, the cells were washed twice with 1X Assay Buffer provided in the kit. Images of autophagic cells were captured using a fluorescent microscope (BX51; Olympus) with a FITC filter (excitation, $480 \mathrm{~nm}$; emission, $530 \mathrm{~nm})$.

Western blot analysis. For whole cell lysate preparations, cultured cells were washed twice with cold PBS and immersed in radioimmunoprecipitation assay buffer (Beyotime Institute of Biotechnology). The cell lysate was harvested and centrifuged at $12,000 \mathrm{x}$ g for $10 \mathrm{~min}$ at $4^{\circ} \mathrm{C}$, and the supernatant was subsequently collected. The protein concentration was determined using the bicinchoninic acid protein assay (Beyotime Institute of Biotechnology). Identical protein samples $(20 \mu \mathrm{g} / \mu \mathrm{l})$ were separated by $10 \%$ sodium dodecyl sulfate-polyacrylamide gel electrophoresis and transferred to a polyvinylidene difluoride membrane (EMD Millipore, Billerica, MA, USA). The membrane was blocked with $5 \%$ fat-free milk at room temperature for $1 \mathrm{~h}$, and was then incubated with the following primary antibodies: Rabbit anti-B-cell lymphoma 2 (Bcl-2; 1:800; cat. no. sc-492; Bioworld Technology Inc., St. Louis Park, MN, USA), rabbit anti-Bcl-2-associated X protein (Bax; 1:800; cat. no. BS1030; Bioworld Technology Inc.), rabbit anti-caspase-3 (1:1,000; cat. no. ab52314; Abcam, Cambridge, MA, USA), rabbit monoclonal anti-human cleaved caspase-3 (1:1,000; Abcam; cat. no. ab184787), anti-LC3 (1:1,000, cat. no. 3868; Cell Signaling Technology, Inc., Danvers, MA, USA), rabbit anti-Akt (1:1,000; cat. no. 4691; Cell Signaling Technology, Inc.), rabbit anti-phosphorylated (p)-Akt (1:1,000; cat. no. 4060; Cell Signaling Technology, Inc.), rabbit anti-mTOR (1:1,000; Abcam; cat. no. ab2732), rabbit anti-p-mTOR (1:1,000; cat. no. ab84400; Abcam) and anti- $\beta$-actin (1:800; cat. no. AP0733; Bioworld Technology, Inc.) at $4^{\circ} \mathrm{C}$ overnight. The membrane was subsequently washed three times for 15 min with Tris-buffered saline containing $0.1 \%$ Tween, and incubated with horseradish peroxidase-conjugated secondary antibodies (1:500; Santa Cruz Biotechnology, Inc., Dallas, TX, USA) for $1 \mathrm{~h}$ at room temperature. The membrane was visualized using a western blotting detection system (Bio-Rad Laboratories, Inc., Hercules, CA, USA). The digital image was analyzed for densitometry using ImageJ (version 1.49; National Institutes of Health, Bethesda, MD, USA). 

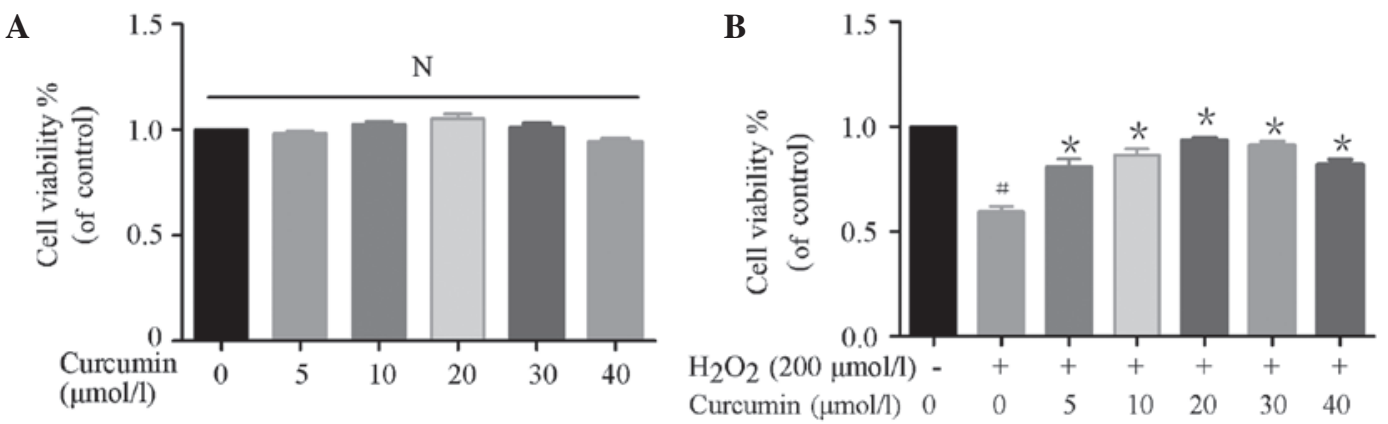

Figure 1. Detection of EA.hy926 cell viability. (A) Curcumin (0-40 $\mu \mathrm{mol} / 1)$ did not significantly affect cell viability, as determined by Cell Counting kit- 8 assay. (B) Curcumin $(5-40 \mu \mathrm{mol} / \mathrm{l})$ prevented hydrogen peroxide $\left(\mathrm{H}_{2} \mathrm{O}_{2}\right)$-induced cytotoxicity in a dose-dependent manner. Data are presented as the mean \pm standard deviation. $\mathrm{N}$, not significant as compared with the control; ${ }^{2} \mathrm{P}<0.05$ vs. the control group; ${ }^{*} \mathrm{P}<0.05$ vs. the $\mathrm{H}_{2} \mathrm{O}_{2}$-treated group.

A

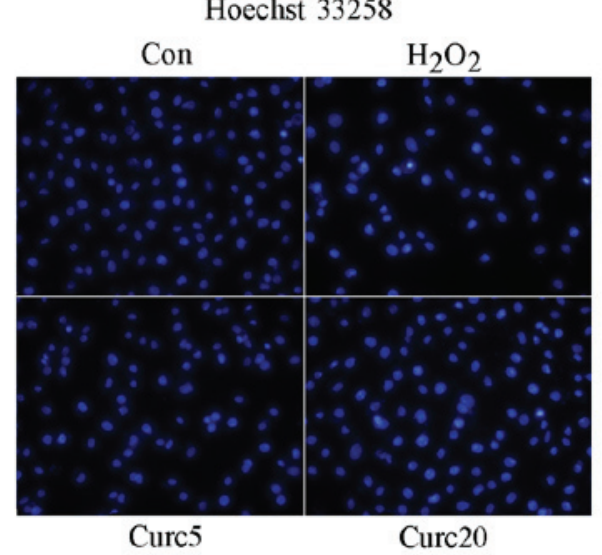

B

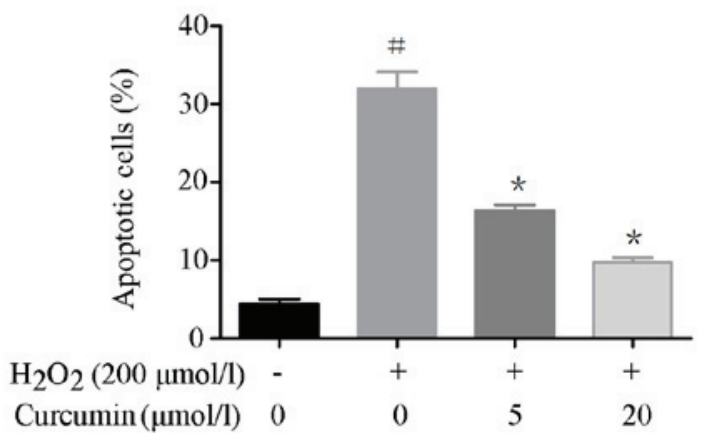

Figure 2. Hoechst 33258 staining of apoptotic cells. (A) Hoechst 33258 staining. Bright blue fluorescence represents apoptosis (magnification, x200). (B) Analysis of the percentage of apoptotic cells. The apoptotic index was significantly lower in the curcumin-pretreated cells, as compared with the hydrogen peroxide $\left(\mathrm{H}_{2} \mathrm{O}_{2}\right)$-treated cells in a concentration-dependent manner. Data are presented as the mean \pm standard deviation. ${ }^{\#} \mathrm{P}<0.05$ vs. the control group; ${ }^{*} \mathrm{P}<0.05$ vs. the $\mathrm{H}_{2} \mathrm{O}_{2}$-treated group. Con, control group; $\mathrm{H}_{2} \mathrm{O}_{2}, \mathrm{H}_{2} \mathrm{O}_{2}$-treated group; Curc5, $5 \mu \mathrm{mol} / 1$ curcumin-treated group; Curc20, $20 \mu$ mol/1 curcumin-treated group.

Statistical analysis. GraphPad Prism 5 (GraphPad Software, Inc., La Jolla, CA, USA) and SPSS 13.0 software (SPSS, Inc., Chicago, IL, USA) were used for statistical analysis and graphing. All data are presented as the mean \pm standard deviation. Statistical differences among groups were analyzed by one-way analysis of variance. $\mathrm{P}<0.05$ was considered to indicate a statistically significant difference.

\section{Results}

Curcumin protects against $\mathrm{H}_{2} \mathrm{O}_{2}$-induced cytotoxicity in EA.hy926 cells. EA.hy926 cells were pretreated with curcumin $(0,5,10,20,30$ or $40 \mu \mathrm{mol} / \mathrm{l})$ for $4 \mathrm{~h}$, and were then co-incubated with $200 \mu \mathrm{mol} / 1 \mathrm{H}_{2} \mathrm{O}_{2}$ for an additional $4 \mathrm{~h}$, in order to determine the effects of curcumin on $\mathrm{H}_{2} \mathrm{O}_{2}$-induced cell death. As shown in Fig. 1A, curcumin (0-40 $\mu \mathrm{mol} / \mathrm{l})$ did not significantly affect viability of the EA.hy926 cells. In addition, curcumin (5-40 $\mu \mathrm{mol} / \mathrm{l}$ ) prevented $\mathrm{H}_{2} \mathrm{O}_{2}$-induced cytotoxicity (Fig. 1B).

Curcumin mitigates $\mathrm{H}_{2} \mathrm{O}_{2}$-induced apoptosis in EA.hy926 cells. To examine the effects of curcumin on the apoptosis of EA.hy 926 cells, Hoechst 33258 staining was conducted and the expression levels of apoptosis-associated proteins were detected following curcumin pretreatment. Hoechst 33258 staining was used to assess DNA fragmentation. As shown in Fig. 2A and B, the percentage of apoptotic cells was significantly reduced in the curcumin-pretreated cells in a concentration-dependent manner, as compared with the $\mathrm{H}_{2} \mathrm{O}_{2}$-treated cells. The expression levels of apoptosis regulatory proteins, including caspase-3, Bax and Bcl-2 were detected, in order to confirm the anti-apoptotic effect of curcumin on $\mathrm{H}_{2} \mathrm{O}_{2}$-induced cells. As shown in Fig. 3A-G, the expression levels of cleaved caspase- 3 and Bax were increased following treatment with $\mathrm{H}_{2} \mathrm{O}_{2}$, as compared with the control. Curcumin pretreatment significantly decreased the expression levels of $\mathrm{H}_{2} \mathrm{O}_{2}$-induced cleaved caspase-3 and Bax in EA.hy926 cells. In addition, the expression levels of the anti-apoptotic protein Bcl-2 were decreased following $\mathrm{H}_{2} \mathrm{O}_{2}$ treatment, and were increased in a concentration-dependent manner following curcumin pretreatment. The increase in Bax/Bcl-2 ratio induced by $\mathrm{H}_{2} \mathrm{O}_{2}$ was inhibited by curcumin.

Curcumin promotes autophagy in $\mathrm{H}_{2} \mathrm{O}_{2}$-treated EA.hy926 cells. In order to detect autophagy and evaluate the extent of autophagosome formation in $\mathrm{H}_{2} \mathrm{O}_{2}$-treated cells, a FITC-labeled LC3 antibody from the CYTO-ID ${ }^{\circledR}$ Autophagy Detection kit (Enzo Life Sciences, Inc.) was used. When autophagy takes place in mammalian cells, LC3 content, particularly LC3-II 
A

D

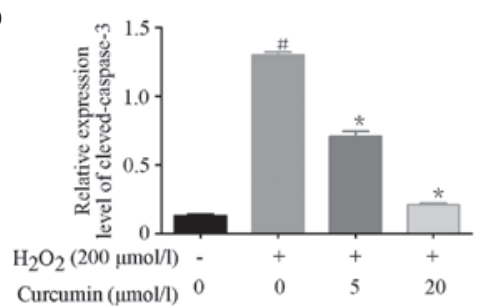

cleavedcaspase-3
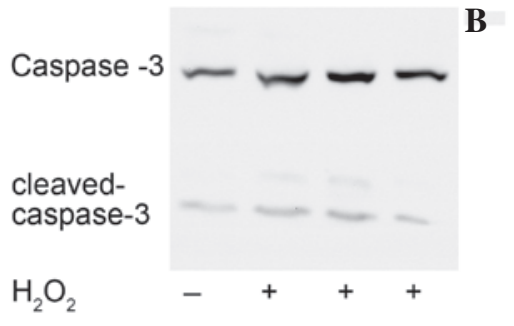

E
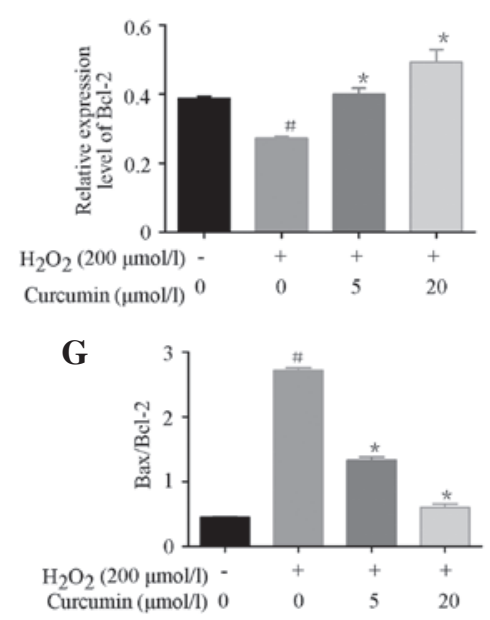

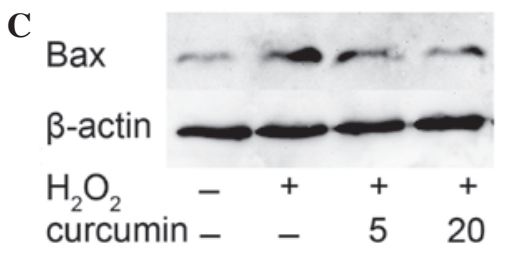

F

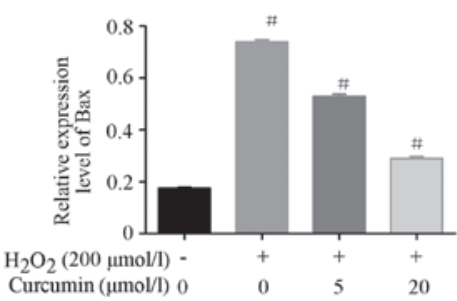

Figure 3. Expression levels of apoptosis regulatory proteins. (A-C) Western blot analysis of cleaved caspase-3, B-cell lymphoma 2 (Bcl-2) and Bcl-2-associated X protein (Bax). $\beta$-actin was used as an internal control. (D-F) Densitometric analysis of cleaved caspase-3, Bcl-2 and Bax normalized to $\beta$-actin. (G) Analysis of the ratio between the expression of Bcl-2 and Bax. Data are presented as the mean \pm standard deviation. ${ }^{\#} \mathrm{P}<0.05$ vs. the control group; ${ }^{*} \mathrm{P}<0.05$ vs. the $\mathrm{H}_{2} \mathrm{O}_{2}$-treated group.

content, is significantly increased. LC3-II is considered an appropriate marker of autophagy activation, since it is a vital protein in autophagosome formation (16). As shown in Fig. 4A and B, as compared with the control group, there was no significant difference in LC3-II content in the $\mathrm{H}_{2} \mathrm{O}_{2}$-treated cells; however, there was a significant increase in LC3 expression in the rapamycin-treated cells, and a slight increase in expression in the curcumin-pretreated cells. Lipidation of LC3 is essential for autophagy to proceed. As shown in Fig. $4 \mathrm{C}$ and $\mathrm{D}$, following an increase in autophagy, the protein expression levels of LC3-II were significantly higher in the curcumin-pretreated cells compared with in the control and $\mathrm{H}_{2} \mathrm{O}_{2}$-treated cells. Furthermore, the results of western blotting indicated that the protein expression levels of LC3-II were significantly higher in the curcumin-pretreated cells, as compared with in the control and $\mathrm{H}_{2} \mathrm{O}_{2}$-treated cells.

Curcumin downregulates the Akt/mTOR signaling pathway in $\mathrm{H}_{2} \mathrm{O}_{2}$-treated EA.hy926 cells. To further evaluate the mechanisms and signaling pathways underlying curcumin-induced autophagy, the activation status of mTOR and its upstream regulator Akt were determined by western blotting. As shown in Fig. 5, the expression levels of p-Akt and p-mTOR were increased in the $\mathrm{H}_{2} \mathrm{O}_{2}$-treated cells. However, the expression levels of p-Akt and p-mTOR were significantly decreased in the curcumin-pretreated cells in a concentration-dependent manner. These results indicate that curcumin was able to inhibit the expression of the autophagy suppressor mTOR in EA.hy926 cells, and this was associated with the cell-specific modulation of the mTOR upstream regulator, Akt.

\section{Discussion}

The results of the present study demonstrated that pretreatment with curcumin alleviated $\mathrm{H}_{2} \mathrm{O}_{2}$-induced cytotoxicity in EA.hy926 cells. In addition, pretreatment with curcumin inhibited oxidative stress-induced apoptosis and activated adaptive autophagy in EA.hy926 cells. These results indicated that the protective effects of curcumin were dependent on regulation of the Akt/mTOR signaling pathway.

The EA.hy926 human umbilical vein cell line is produced by hybridizing human umbilical endothelial cells (HUVECs) with the A549 epithelial cell line. EA.hy926 cells are widely used as a replacement for HUVECs in in vitro experiments, and $\mathrm{H}_{2} \mathrm{O}_{2}$ is widely used to generate models of oxidative stress. Oxidative stress is capable of activating the mitochondrial signaling pathway and has a pivotal role in the pathogenesis of cardiovascular disease, including ischemic heart disease, hypertension and heart failure (17). Therefore, the elimination of excessive intracellular ROS and prevention of oxidative stress may be an effective intervention for the treatment of these diseases.

Curcumin, which is a major effective ingredient extracted from a traditional Chinese herbal medicine, exerts potent antioxidative effects and has been widely used to prevent and treat cardiovascular disease, including atherosclerosis $(18,19)$. However, the mechanisms underlying the protective effects of curcumin vary considerably between studies. Previously, Notch, Toll-like receptor (TLR)2, ROS-relative TLR4-mitogen-activated protein kinases/nuclear factor- $\kappa \mathrm{B}$, glycogen synthase kinase-3 $\beta$, peroxisome proliferator-activated 

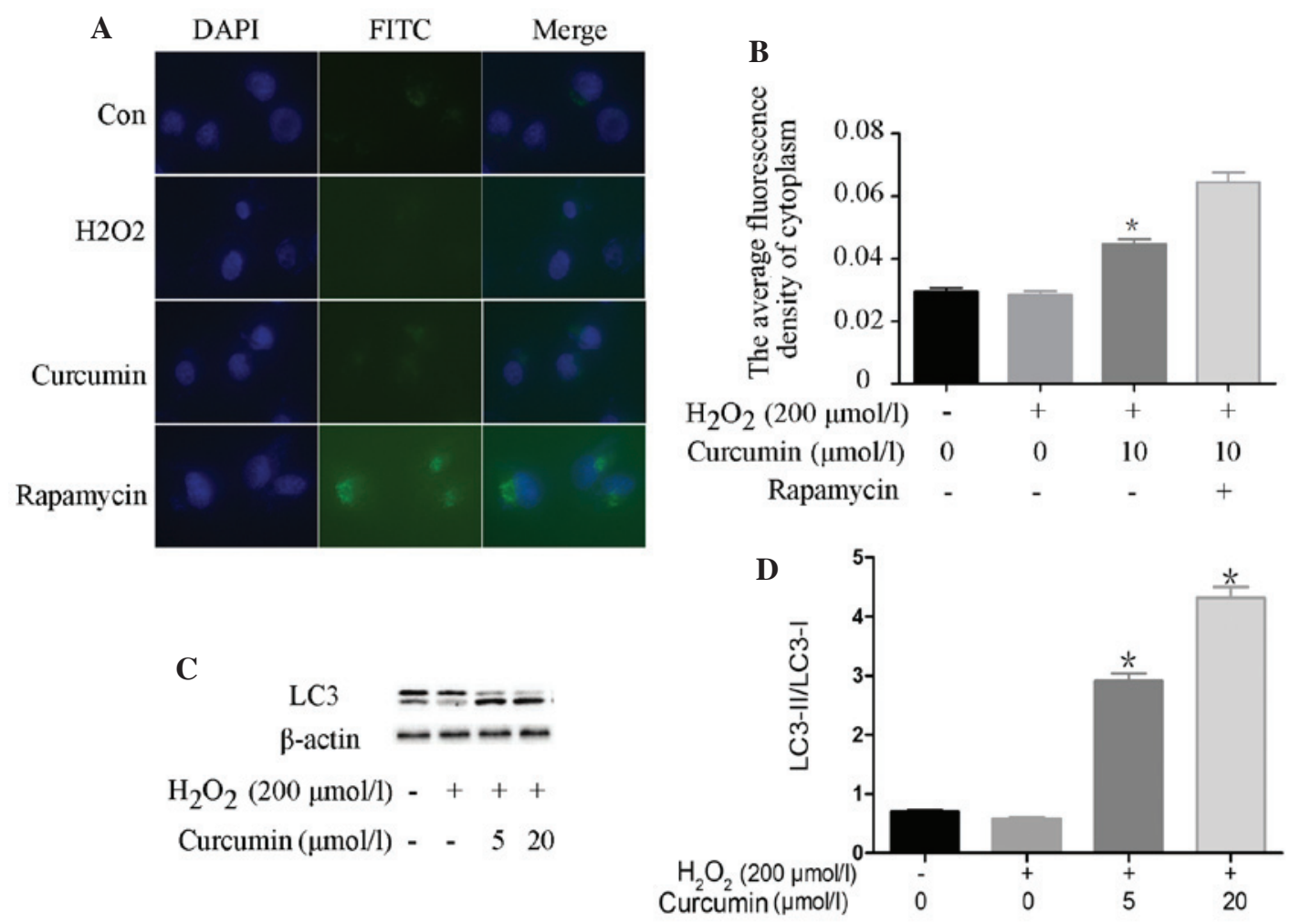

Figure 4. Treatment with curcumin induced autophagy in hydrogen peroxide $\left(\mathrm{H}_{2} \mathrm{O}_{2}\right)$-treated EA.hy926 cells. (A) Detection of autophagosome formation. Blue fluorescence represents the nucleus and green fluorescence represents autophagy (magnification, $\mathrm{x} 200$ ). Rapamycin was used as a positive control. (B) Analysis of autophagosome formation. (C and D) Western blot analysis of microtubule-associated protein 1A/1B-light chain 3 (LC3) normalized to $\beta$-actin. Data are presented as the mean \pm standard deviation. ${ }^{"} \mathrm{P}<0.05$ vs. the control group; ${ }^{*} \mathrm{P}<0.05$ vs. the $\mathrm{H}_{2} \mathrm{O}_{2}$-treated group. Con, control group.

A

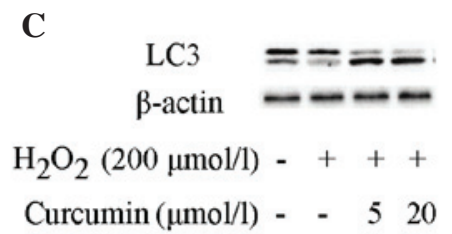

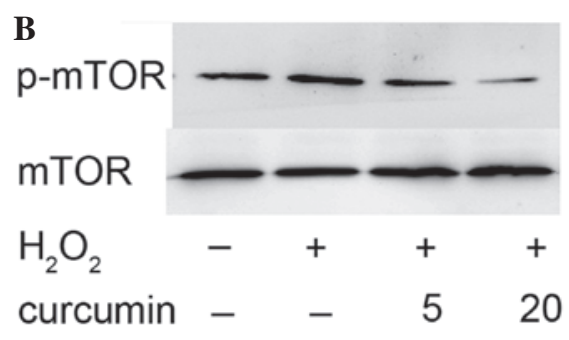

D

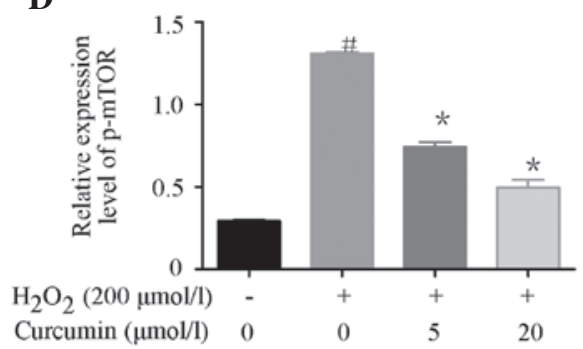

Figure 5. Phosphorylated (p)-Akt and p-mammalian target of rapamycin (mTOR) protein expression in EA.hy926 cells. (A) Western blot analysis of total Akt and p-Akt, and (B) total mTOR and p-mTOR expression. Densitometric analysis of (C) p-Akt and (D) p-mTOR expression. Data are presented as the mean \pm standard deviation. ${ }^{\prime \prime} \mathrm{P}<0.05$ vs. the control group; ${ }^{*} \mathrm{P}<0.05$ vs. the $\mathrm{H}_{2} \mathrm{O}_{2}$-treated group.

receptor $\gamma$, and Sirtuin $1(2,20-24)$ have been reported to have a role in the protective effects of curcumin on oxidative stress-injured endothelial cells. In our previous study, curcumin was shown to mitigate $\mathrm{H}_{2} \mathrm{O}_{2}$-induced myocardial damage by inhibiting the expression of monocyte chemoattractant protein-1 (25); however, the role of autophagy in this process has not been reported. To the best of our knowledge, no studies have yet reported that curcumin activates adaptive autophagy 
in oxidative stress-injured endothelial cells; however, considerable evidence has demonstrated that curcumin induces cancer cell apoptosis via autophagy activation (26-31). Curcumin, or its analogue, have previously been reported to induce cell death in colon cancer, uterine leiomyosarcoma, astrocytoma, ovarian cancer, lung adenocarcinoma and cutaneous T-cell lymphoma cells (26-31) by activating autophagy. In the present study, curcumin attenuated $\mathrm{H}_{2} \mathrm{O}_{2}$-induced cell death by activating adaptive autophagy in EA.hy926 cells.

Autophagy and apoptosis are two closely regulated pathways through which superfluous, damaged, or aged cells or organelles are eliminated. In addition, autophagy is a process by which cells adapt their metabolism to environmental or intracellular stress conditions, including starvation, endoplasmic reticulum stress, hypoxia, ischemia/reperfusion injury, pathogens and oxidative stress. Autophagy generates metabolic substrates that meet the bioenergetic needs of cells, and thereby allows for adaptive protein synthesis by the catabolism of macromolecules (32-34). Autophagy enables cells to adapt to stress, in order to avoid cell death; however, autophagy is also an alternative pathway that may lead to cell death (35-37). Autophagy and apoptosis can be initiated in response to similar stimuli, whereas in some situations autophagy and apoptosis are initiated in a mutually exclusive manner. The relationship between autophagy and apoptosis is complex. There are several examples in which the induction of autophagy promotes the activation of apoptosis; however, autophagy also arises from the inhibition of apoptosis and protects cells from cell death (38), and sometimes autophagy inhibits the induction of apoptosis. High dose $\mathrm{H}_{2} \mathrm{O}_{2}$ can induce cellular damage due to oxidative stress. Oxidative stress increases the permeability of the lysosomal membrane, and induces the uncoupling of oxidation and phosphorylation reactions in the mitochondria, resulting in the activation of various cell death programs (39). At a low level of oxidative stress, autophagy protects the cell against major harm by degrading damaged mitochondria prior to cytochrome $c$ release (40). In the present study, a significant decrease in cell viability was detected in the $\mathrm{H}_{2} \mathrm{O}_{2}$-treated $(200 \mu \mathrm{mol} / \mathrm{l})$ EA.hy926 cells. In addition, the levels of apoptosis were increased, whereas autophagy exhibited no significant change. When pretreated with curcumin, $\mathrm{H}_{2} \mathrm{O}_{2}$-induced EA.hy926 cell death was reduced, the rate of apoptosis was reduced and autophagy was increased. Therefore, these results suggested that $\mathrm{H}_{2} \mathrm{O}_{2}(200 \mu \mathrm{mol} / \mathrm{l})$ was able to induce EA.hy926 cell apoptosis but had no effect on autophagy, whereas curcumin pretreatment attenuated apoptosis in $\mathrm{H}_{2} \mathrm{O}_{2}$-treated EA.hy926 cells by activating autophagy. These data demonstrated that curcumin may induce autophagy, in order to protect endothelial cells.

The Bcl-2 protein family, which is comprised of anti- and pro-apoptotic members, consists of important mitochondrial regulators during cell apoptosis. As compared with Bax, Bcl-2 blocks cytochrome $c$ release, inhibits caspase activity and suppresses cell apoptosis (41). Therefore, alterations to the Bcl-2/Bax ratio influences apoptotic balance. In the present study, curcumin significantly inhibited Bax expression, and increased Bcl-2 expression in cells undergoing oxidative stress, resulting in a reduced $\mathrm{Bax} / \mathrm{Bcl}-2$ ratio and increased cell viability.
The regulation of autophagy is complex and involves numerous pathways. The mTOR pathway is the most extensively studied network with regards to autophagy regulation due to its ability to sense nutrient state, growth factor availability and stress (42). Upstream of mTOR complex 1 (mTORC1) is the tuberous sclerosis complex (TSC)1-TSC2 inhibitory complex, which functions as an upstream activator of mTOR. The TSC1-TSC2 complex inactivates Rheb, which inhibits mTOR signaling, leading to the subsequent activation of autophagy. mTORC1 is able to directly sense amino acid concentration and energy state, whereas the PI3K/Akt axis can sense growth factor status. mTOR complex 2 is an inhibitor that decreases the extent of Akt-induced mTORC1 activation (43). The present study demonstrated that $\mathrm{H}_{2} \mathrm{O}_{2}$ induced the phosphorylation of mTOR, and this activation was inhibited by curcumin. These findings are consistent with the view that mTOR regulates autophagy by controlling phosphorylation (44). Indeed, curcumin pretreatment led to decreased Akt phosphorylation, which was associated with mTOR inhibition and autophagy. These results indicated that Akt is involved in curcumin-induced mTOR suppression and autophagy. However, the underlying mechanisms of action require further study.

In conclusion, the results of the present study demonstrated that oxidative stress may promote cell death in EA.hy926 cells, and pre-treatment with curcumin suppresses cell death by inducing autophagy via regulation of the Akt/mTOR pathway.

\section{Acknowledgements}

The present study was supported by grants from the Fourth Period Project '333' of Jiangsu Province (grant no. BRA2012207), the Priority Academic Program Development of Jiangsu Higher Education Institutions (grant no. BL2012011) and the National Natural Science Foundation of China (grant no. 81170102/H0203).

\section{References}

1. Kim YS, Ahn Y, Hong MH, Joo SY, Kim KH, Sohn IS, Park HW, Hong YJ, Kim JH, Kim W, et al: Curcumin attenuates inflammatory responses of TNF-alpha-stimulated human endothelial cells. J Cardiovasc Pharmacol 50: 41-49, 2007.

2. Lubbad A, Oriowo MA and Khan I: Curcumin attenuates inflammation through inhibition of TLR-4 receptor in experimental colitis. Mol Cell Biochem 322: 127-135, 2009.

3. Miriyala S, Panchatcharam $M$ and Rengarajulu P: Cardioprotective effects of curcumin. Adv Exp Med Biol 595: 359-377, 2007.

4. Aggarwal BB and Harikumar KB: Potential therapeutic effects of curcumin, the anti-inflammatory agent, against neurodegenerative, cardiovascular, pulmonary, metabolic, autoimmune and neoplastic diseases. Int J Biochem Cell Biol 41: 40-59, 2009.

5. Nazam Ansari M, Bhandari U and Pillai KK: Protective role of curcumin in myocardial oxidative damage induced by isoproterenol in rats. Hum Exp Toxicol 26: 933-938, 2007.

6. Naik SR, Thakare VN and Patil SR: Protective effect of curcumin on experimentally induced inflammation, hepatotoxicity and cardiotoxicity in rats: Evidence of its antioxidant property. Exp Toxicol Pathol 63: 419-431, 2011.

7. Zanchetti A, Hennig M, Hollweck R, Bond G, Tang R, Cuspidi C, Parati G, Facchetti R and Mancia G: Baseline values but not treatment-induced changes in carotid intima-media thickness predict incident cardiovascular events in treated hypertensive patients: Findings in the European Lacidipine Study on Atherosclerosis (ELSA). Circulation 120: 1084-1090, 2009. 
8. Motterlini R, Foresti R, Bassi R and Green CJ: Curcumin, an antioxidant and anti-inflammatory agent, induces heme oxygenase-1 and protects endothelial cells against oxidative stress. Free Radic Biol Med 28: 1303-1312, 2000

9. Green DR: Apoptotic pathways: Ten minutes to dead. Cell 121: 671-674, 2005.

10. Mizushima N, Levine B, Cuervo AM and Klionsky DJ: Autophagy fights disease through cellular self-digestion. Nature 451: 1069-1075, 2008.

11. Takagi H, Matsui Y, Hirotani S, Sakoda H, Asano T and Sadoshima J: AMPK mediates autophagy during myocardial ischemia in vivo. Autophagy 3: 405-407, 2007.

12. Cao DJ, Wang ZV, Battiprolu PK, Jiang N, Morales CR, Kong Y, Rothermel BA, Gillette TG and Hill JA: Histone deacetylase (HDAC) inhibitors attenuate cardiac hypertrophy by suppressing autophagy. Proc Natl Acad Sci USA 108: 4123-4128, 2011.

13. Sinnberg T, Lasithiotakis K, Niessner H, Schittek B, Flaherty KT, Kulms D, Maczey E, Campos M, Gogel J, Garbe C and Meier F: Inhibition of PI3K-AKT-mTOR signaling sensitizes melanoma cells to cisplatin and temozolomide. J Invest Dermatol 129: 1500-1515, 2009.

14. Hietakangas V and Cohen SM: Regulation of tissue growth through nutrient sensing. Annu Rev Genet 43: 389-410, 2009.

15. Kamada Y, Yoshino K, Kondo C, Kawamata T, Oshiro N Yonezawa K and Ohsumi Y: Tor directly controls the Atg1 kinase complex to regulate autophagy. Mol Cell Biol 30: 1049-1058, 2010.

16. Tanida I, Ueno T and Kominami E: LC3 conjugation system in mammalian autophagy. Int J Biochem Cell Biol 36: 2503-2518, 2004.

17. Ong SB and Gustafsson AB: New roles for mitochondria in cell death in the reperfused myocardium. Cardiovasc Res 94: 190-196, 2012.

18. Kowluru RA and Kanwar M: Effects of curcumin on retinal oxidative stress and inflammation in diabetes. Nutr Metab (Lond) 4: 8, 2007.

19. Quiles JL, Mesa MD, Ramírez-Tortosa CL, Aguilera CM, Battino M, Gil A and Ramírez-Tortosaet MC: Curcuma longa extract supplementation reduces oxidative stress and attenuates aortic fatty streak development in rabbits. Arterioscler Thromb Vasc Biol 22: 1225-1231, 2002

20. Yang Y, Duan W, Liang Z, Yi W, Yan J, Wang N, Li Y, Chen W, Yu S, Jin Z and Yi D: Curcumin attenuates endothelial cell oxidative stress injury through Notch signaling inhibition. Cell Signal 25: 615-629, 2013

21. Meng Z, Yan C, Deng Q, Gao DF and Niu XL: Curcumin inhibits LPS-induced inflammation in rat vascular smooth muscle cells in vitro via ROS-relative TLR4-MAPK/NF- $\kappa \mathrm{B}$ pathways. Acta Pharmacol Sin 34: 901-911, 2013.

22. Chanoit G, Lee S, Xi J, Zhu M, Mclntosh RA, Mueller RA and $\mathrm{Xu} \mathrm{Z}$ : Exogenous zinc protects cardiac cells from reperfusion injury by targeting mitochondrial permeability transition pore through inactivation of glycogen syntheses kinase-3beta. Am J Physiol Heart Circ Physiol 295: H1227-H1233, 2008.

23. Blanquicett C, Kang BY, Ritzenthaler JD, Jones DP and Hart CM: Oxidative stress modulates PPAR gamma in vascular endothelial cells. Free Radic Biol Med 48: 1618-1625, 2010.

24. Chung S, Yao H, Caito S, Hwang JW, Arunachalam G and Rahman I: Regulation of SIRT1 in cellular functions: Role of polyphenols. Arch Biochem Biophys 501: 79-90, 2010.

25. Guo SY and Long MZ: Effects of curcumin on expression of MCP-1 induced by $\mathrm{H}_{2} \mathrm{O}_{2}$ in myocardial cell. Nanjing Yi Ke Da Xue Xue Bao 4: 442-444, 2010 (In Chinese).
26. Basile V, Belluti S, Ferrari E, Gozzoli C, Ganassi S, Quaglino D, Saladini $M$ and Imbriano C: bis-Dehydroxy-Curcumin triggers mitochondrial-associated cell death in human colon cancer cells through ER-stress induced autophagy. PLoS One 8: e53664, 2013.

27. Li B, Takeda T, Tsuiji K, Wong TF, Tadakawa M, Kondo A, Nagase $S$ and Yaegashi N: Curcumin induces cross-regulation between autophagy and apoptosis in uterine leiomyosarcoma cells. Int J Gynecol Cancer 23: 803-808, 2013.

28. Romero-Hernández M A, Eguía-Aguilar P Perézpeña-DiazConti M, Rodríguez-Leviz A, Sadowinski-Pine S, Velasco-Rodríguez LA, Cáceres-Cortés JR and Arenas-Huertero F: Toxic effects induced by curcumin in human astrocytoma cell lines. Toxicol Mech Methods 23: 650-659, 2013.

29. Qu W, Xiao J, Zhang H, Chen Q, Wang Z, Shi H, Gong L, Chen J, Liu Y, Cao R and Lv J: B19, a novel monocarbonyl analogue of curcumin, induces human ovarian cancer cell apoptosis via activation of endoplasmic reticulum stress and the autophagy signaling pathway. Int J Biol Sci 9: 766-777, 2013.

30. Xiao K, Jiang J, Guan C, Dong C, Wang G, Bai L, Sun J, Hu C and Bai C: Curcumin induces autophagy via activating the AMPK signaling pathway in lung adenocarcinoma cells. J Pharmacol Sci 123: 102-109, 2013.

31. Yosifov DY, Kaloyanov KA, Guenova ML, Prisadashka K, Balabanova MB, Berger MR and Konstantinov SM: Alkylphosphocholines and curcumin induce programmed cell death in cutaneous T-cell lymphoma cell lines. Leuk Res 38: 49-56, 2014.

32. Rubinsztein DC, Gestwicki JE, Murphy LO and Klionsky DJ: Potential therapeutic applications of autophagy. Nat Rev Drug Discov 6: 304-312, 2007.

33. Meléndez A and Neufeld TP: The cell biology of autophagy in metazoans: A developing story. Development 135: 2347-2360, 2008.

34. Yang Z and Klionsky DJ: Eaten alive: A history of macroautophagy. Nat Cell Biol 12: 814-822, 2010.

35. Baehrecke EH: Autophagy: Dual roles in life and death? Nat Rev Mol Cell Biol 6: 505-510, 2005.

36. Mariño G, Niso-Santano M, Baehrecke EH and Kroemer G: Self-consumption: The interplay of autophagy and apoptosis. Nat Rev Mol Cell Biol 15: 81-94, 2014.

37. Kroemer G and Jäättelä M: Lysosomes and autophagy in cell death control. Nat Rev Cancer 5: 886-897, 2005.

38. Lum JJ, DeBerardinis RJ and Thompson CB: Autophagy in metazoans: Cell survival in the land of plenty. Nat Rev Mol Cell Biol 6: 439-448, 2005.

39. Kubota C, Tor S, Hou N, Saito N, Yoshimoto Y, Imai H and Takeuchi T: Constitutive reactive oxygen species generation from autophagosome/lysosome in neuronal oxidative toxicity. J Biol Chem 285: 667-674, 2010.

40. Kiffin R, Bandyopadhyay U and Cuervo AM: Oxidative stress and autophagy. Antioxid Redox Signal 8: 152-162, 2006.

41. Fischer U and Schulze-Osthoff K: New approaches and therapeutics targeting apoptosis in disease. Pharmacol Rev 57: $187-215,2005$.

42. Jung CH, Ro SH, Cao J, Otto NM and Kim DH: mTOR regulation of autophagy. FEBS Lett 584: 1287-1295, 2010.

43. Hay N and Sonenberg N: Upstream and downstream of mTOR. Genes Dev 18: 1926-1945, 2004.

44. Alers S, Löffler AS, Wesselborg S and Stork B: Role of AMPK-mTOR-Ulk1/2 in the regulation of autophagy: Cross talk, shortcuts, and feedbacks. Mol Cell Biol 32: 2-11, 2012. 